\title{
Aspectos Relacionados à Precocidade Sexual em Bovinos Machos da Raça Nelore, PO.
}

\author{
Antonio E. D. Feliciano Silva ${ }^{1 *}$, Maria M. Unanian ${ }^{1}$, Alzira Roza e Silva ${ }^{2}$ \\ ${ }^{I}$ EMBRAPA-Cenargen, SAIN-Parque Rural, Final Av. W5 Norte, Brasília/DF; ${ }^{2}$ Departamento de Fisiologia, \\ Faculdade de Medicina ,USP, Ribeirão Preto - SP - Brasil.
}

\begin{abstract}
The sexual precocity was studied on 79 Nelore pure breed bovine males ten to 16 month of age. All animals were avaluated for scrotal circumference (CE), testosterone concentration (Testo) and onset of the first spermatozoa in

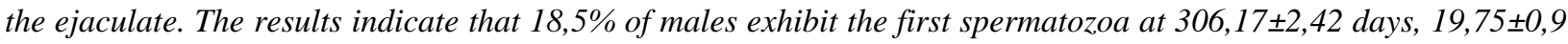

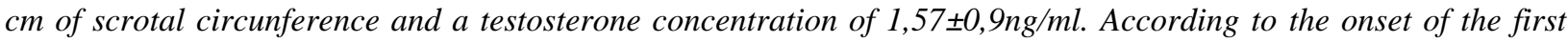

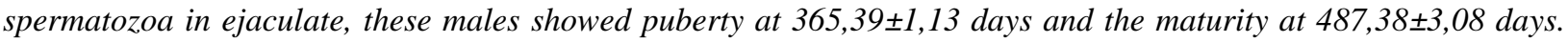
The results indicate the existence of Nelore pure breed males presenting sexual activity at ages bellow that described in the literature, therefore beeing considered precocious.
\end{abstract}

Key words: age of first spermatozoa, scrotal circumference, puberty, bovine, Nelore breed

\section{INTRODUÇÃO}

O conceito da característica precocidade sexual é importante de ponto de vista econômico pois permite o aproveitamento dos animais mais cedo encurtando com isso o intervalo entre gerações.

Em bovinos da raça Nelore, que representam cerca de $72 \%$ do rebanho nacional (Unanian, 1997), existem poucos estudos (Cardoso \& Godinho, 1979; Frenau et al., 1996) descrevendo as modificações anatômicas e fisiológicas, principalmente as testiculares, que caracterizam o inicio da atividade reprodutiva (Curtis \& Amann, 1981).

O bovino da raça Nelore, em função do sistema de criação, é considerado tardio (Entwistle, 1992), este conceito prejudicando o seu aproveitamento e o seu real potencial.

Isto motivou a realização deste trabalho, que teve a finalidade de estudar e estabelecer quando se inicia a vida reprodutiva dos machos desta raça, criados em fazendas de seleção de Nelore, PO.

\section{MATERIAL E MÉTODOS}

O estudo foi desenvolvido em 79 bovinos machos da raça Nelore, de linhagens puras (PO), desde os dez até 16 meses de idade, pertencentes a três fazendas de criação. Os animais nestas fazendas são criados a pasto, recebendo apenas sal mineralizado "ad libitum".

Mensalmente (coletas 1 a 7) foram mensurados o tamanho testicular através da circunferência escrotal (CE) e o peso corporal, e colhidos o sangue por punção da veia jugular e ejaculado através de eletroejaculador (Silva et al., 1988; Swerdloff \& Wang,1996). No sangue, após separado o soro, foi determinada a concentração de testosterona por radioimunoensaio (SILVA et al., 1988), e no ejaculado a presença de espermatozoides.

Para avaliar a precocidade sexual foi observada a idade do aparecimento dos primeiros espermatozoides no ejaculado. Uma vez constatada a presença de espermatozoides no ejaculado o animal era retirado do grupo.

Em função da idade do aparecimento dos primeiros espermatozoides no ejaculado os

\footnotetext{
* Autor para correspondência
} 
animais foram divididos em dois grupos, precoces $(\mathrm{P})$ e não precoces $(\mathrm{NP})$. $\mathrm{O}$ calculo para separar os grupos foi baseado na curva de Gauss, onde os precoces foram situados no extremo inferior da média da idade do aparecimento dos primeiros espermatozoides menos um desvio padrão (Unanian, 1997).

Os resultados foram analisados pela ANOVA (Microcal Origin, 1996), analise de variância e correlações.

\section{RESULTADOS E DISCUSSÃO}

A analise dos parâmetros estudados, em função da idade, mostrou uma diferença significante $(\mathrm{P}<0,05)$ entre os valores da circunferência escrotal, do peso e das concentrações de testosterona. As médias da $\mathrm{CE}$ foram mais elevadas nas ultimas três coletas, e da testosterona aos 365,39 e 487,38 dias (12 e 16 meses, respectivamente) (Tabela 1).

O aumento do nível de testosterona com a idade (Tabela 1) foi relatado também por Foote et al. (1976), sendo proveniente, provavelmente, do aumento do número de células de Leydig e dos túbulos seminíferos, e não propriamente de uma alteração das funções destas estruturas (Amann, 1983), hipótese essa confirmada pelo próprio aumento da circunferência escrotal.
Os picos observados aos 12 meses de idade (Figura 1) foram semelhantes aos descritos por Amann (1983) aos 8 meses em animais da raça Holstein.

Além do primeiro pico aos 12 meses ocorreu um segundo aos 16, sendo que, o primeiro foi atribuído ao aparecimento da puberdade em função do nível de testosterona acima de $1 \mathrm{ng} / \mathrm{ml}$ e do ejaculado contendo, em média, uma concentração de $55 \times 10^{6} \mathrm{spz} / \mathrm{ml}$ e motilidade progressiva de $36 \%$ acima dos critérios adotados para puberdade por Wolf et al. (1965).

Por outro lado o segundo pico ocorrido aos 16 meses de idade pelo nível de testosterona $(2,21$ $\mathrm{ng} / \mathrm{ml}$ ) e ainda da analise do ejaculado (123 x $10^{6} \mathrm{spz} / \mathrm{ml}$ de concentração e $67 \%$ de motilidade progressiva) e pelo conteúdo de alterações patológicas espermáticas $(13 \%)$ é possível considerar que nesta idade ocorreu a maturidade sexual dos machos deste estudo. Estes resultados diferem dos encontrados em animais da raça Nelore por Silva et al. (1988) e Frenau et al. (1996), que foram mais tardios.

Tabela 1. Média ( \pm erro padrão) da idade, níveis séricos de testosterona (Testo), circunferência escrotal (CE) e peso de machos da raça Nelore.

\begin{tabular}{rrrrrr}
\hline Coleta & Número & Idade (dias) & Testo $(\mathrm{ng} / \mathrm{ml}$ & CE $(\mathrm{cm})$ & Peso $(\mathrm{kg})$ \\
\hline 1 & 42 & $306,12 \pm 1,40$ & $0,83 \pm 0,11^{\mathrm{a}}$ & $19,56 \pm 0,34^{\mathrm{a}}$ & $249,43 \pm 08,43$ \\
2 & 57 & $337,79 \pm 1,27$ & $1,27 \pm 0,14^{\mathrm{b}}$ & $20,65 \pm 0,33^{\mathrm{b}}$ & $266,09 \pm 06,83$ \\
3 & 64 & $365,39 \pm 1,13$ & $1,73 \pm 0,21^{\mathrm{bc}}$ & $21,62 \pm 0,33^{\mathrm{c}}$ & $287,55 \pm 06,46$ \\
4 & 51 & $394,94 \pm 1,21$ & $1,35 \pm 0,19^{\mathrm{b}}$ & $22,92 \pm 0,47^{\mathrm{d}}$ & $306,90 \pm 09,04$ \\
5 & 44 & $424,83 \pm 1,32$ & $1,51 \pm 0,17^{\mathrm{bc}}$ & $23,11 \pm 0,39^{\mathrm{d}}$ & $302,85 \pm 08,11$ \\
6 & 33 & $456,64 \pm 1,74$ & $1,69 \pm 0,28^{\mathrm{bc}}$ & $23,90 \pm 0,50^{\mathrm{de}}$ & $316,29 \pm 09,61$ \\
7 & 13 & $487,38 \pm 3,08$ & $2,21 \pm 0,42^{\mathrm{c}}$ & $25,15 \pm 0,58^{\mathrm{e}}$ & $355,31 \pm 17,16$ \\
\hline
\end{tabular}

Valores acompanhados de letras diferentes, dentro da mesma coluna, são significantes ao nível de 5\% pelo teste de "T". 


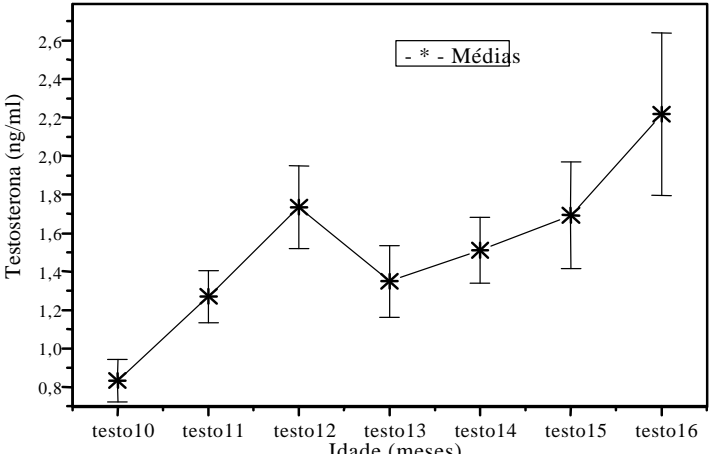

Figura 1 Concentração de testosterona (m

(médias e erro padrão) em função da idade em machos da raça Nelore

Observando ainda o nível de testosterona aos 10 meses de idade (306,12 dias), ou seja a primeira coleta, foi constatado estar este nível próximo do encontrado na puberdade, sugerindo já a existência de uma atividade esteroidogénica das células de Leydig. Segundo Amann (1983), nos machos da raça Holstein, a atividade esteroidogénica das células de Leydig, necessária à produção de testosterona, torna-se intensa entre a $16^{\mathrm{a}}$ e $24^{\mathrm{a}}$ semana (4 a 6 meses) pós-nascimento, e, ainda, que nesta idade estas

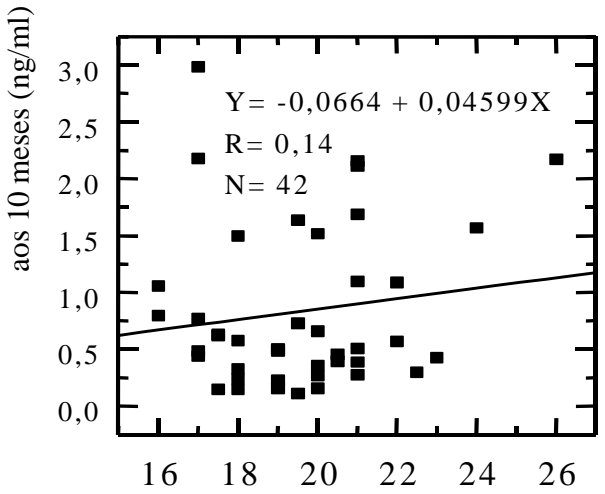

Circunferência escrotal aos 10 meses $(\mathrm{cm})$

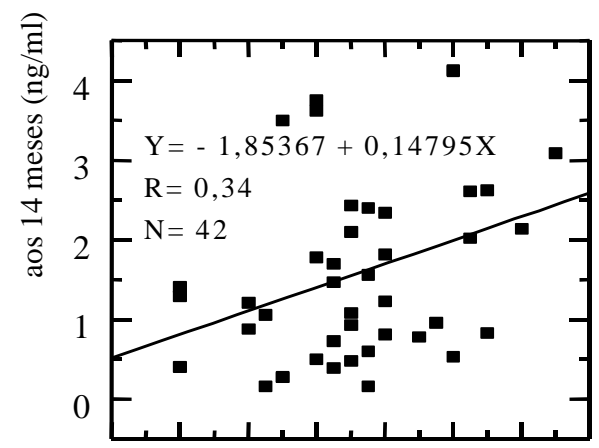

$\begin{array}{llllllll}16 & 18 & 20 & 22 & 24 & 26 & 28 & 30\end{array}$

Circunferência escrotal aos 14 meses $(\mathrm{cm})$ células já existem em grande numero e pleno amadurecimento, conforme os estudos de GE et al. (1996) e Swerdloff et al. (1996). Em função do exposto e da analise dos resultados encontrados neste estudo é possível acreditar que a atividade esteroidogénica nos machos da raça Nelore também deve ter ocorrido antes dos 10 meses de idade como nos animais Holstein. Porém por falta de dados anteriores, e ainda de dados de literatura referentes à raça, torna-se difícil saber se houve alguma atividade esteroidogénica anterior, assumindo-se assim que o inicio desta atividade em machos da raça Nelore ocorre, em média, aos 10 meses de idade. As correlações entre a circunferência escrotal e o nível de testosterona (Figura 2) foram baixas, semelhantes as encontradas em animais de 1 a 2 anos por Zhang et al. (1993).

Estes resultados mostram que a concentração de testosterona em animais jovens não foi influenciada pelo tamanho da CE comprovando a hipótese e os resultados de Lunstra et al. (1978) e Bailey et al. (1996). Segundo estes autores a

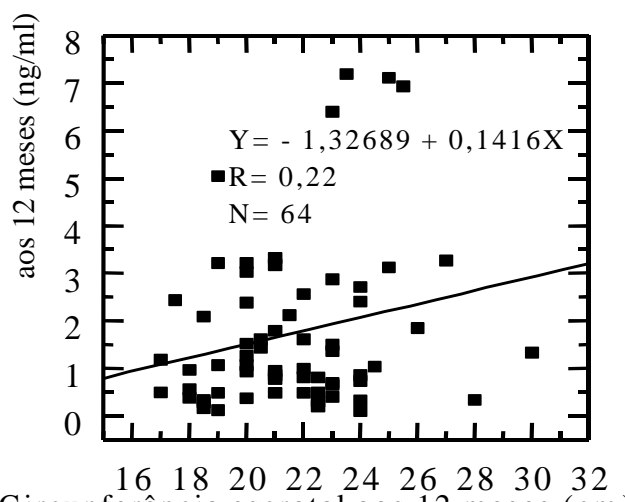

Circunferência escrotal aos 12 meses $(\mathrm{cm})$

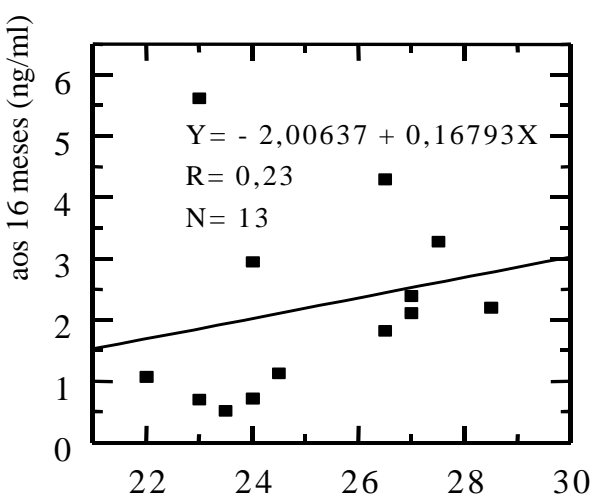

Circunferência escrotal aos 16 meses $(\mathrm{cm})$

Figura 2. Correlação entre a concentração de testosterona e circunferência escrotal 
circunferência escrotal não mede corretamente o estatus produtivo do testículo uma vez que este pode apresentar varias formas, desde alongado ate redondo, como também observado neste trabalho. Testículos de forma alongada normalmente apresentam CE pequena. No entanto, como a produção de testosterona esta em função do numero de células de Leydig, estes testículos podem apresentar uma área contendo suficiente número e grau de desenvolvimento destas células necessárias à produção de testosterona. Assim sendo, é preciso quando avaliar o macho considerar juntamente com a $\mathrm{CE}$ a forma dos testículos para não se interpretar erroneamente o seu potencial reprodutivo.

Mesmo as correlações dos níveis de testosterona com os pesos mensais não foram significantes ( $\mathrm{R}=0,05$ a 0,37 ), ao contrário do esperado em se tratando de animais em crescimento (Amann, 1983), e ainda por serem as correlações do peso e CE altamente significantes $(R=0,61$ a 0,77$)$, como também observado por Coulter \& Foote (1979) e Amann (1983). No entanto, apesar desta última correlação ser alta, estes mesmos autores consideram que apenas o peso não é um parâmetro insuficiente para predizer o tamanho testicular, consequentemente a produção de testosterona, devido a variação destes parâmetros com a idade. Mesmo assim, comparando as correlações do nível de testosterona e peso da primeira e das últimas duas coletas $(10,15$ e 16 meses, respectivamente) com as demais, observou-se serem estas maiores o que poderia ser explicado em função do desenvolvimento testicular ao aparecimento dos primeiros espermatozoides e da maturidade. Nesta última fase ocorreu ainda a maior concentração de testosterona $(2,21 \mathrm{ng} / \mathrm{ml})$, o que permite concluir que o peso, apesar de aparentemente não influenciar o nível de testosterona, é importante para o inicio do desenvolvimento fisiológico como observado por Wolf et al. (1965) e Unanian (1997).

A correlação da concentração de testosterona e o peso ao nascer em função da idade, alem de não significantes, foram negativas $(\mathrm{R}=-0,06 \mathrm{a}-$ $0,47)$, assim como as correlações entre o peso ao nascer e a $C E(R=-0,0004$ a $-0,18)$, o que sugere que o peso ao nascer não influencia o desenvolvimento sexual, ou seja o aparecimento dos primeiros espermatozoides, a puberdade e maturidade.

A idade à precocidade sexual definida pelo aparecimento dos primeiros espermatozoides no ejaculado foi representada através da curva de Gauss (Figura 3).

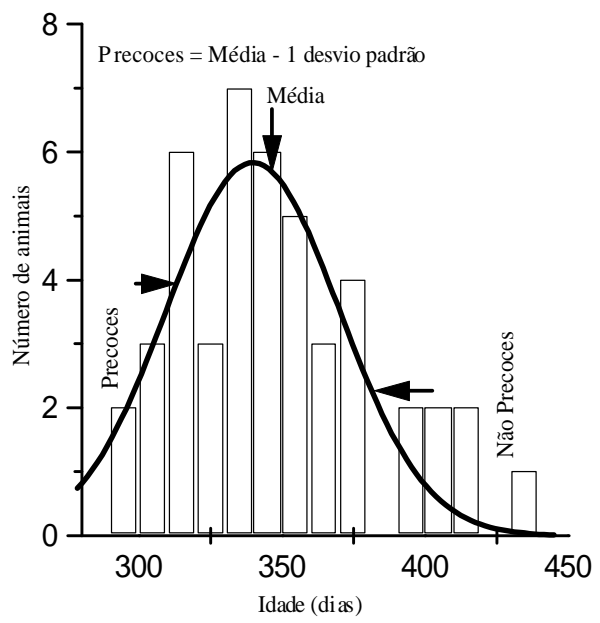

Figura 3. Curva de Gauss para representação dos animais precoces e não precoces

Os resultados indicaram que $18,5 \%$ dos machos da raça Nelore apresentaram os primeiros espermatozoides no ejaculado entre 292 e 316 dias de idade, numa média de 306 dias (10 meses), tendo sido considerados machos precoces com idade significativamente menor dos demais $(\mathrm{P}<0,05)$ (Tabela 2$)$.

Tabela 2. Média ( \pm erro padrão) da idade, circunferência escrotal (CE) e níveis séricos de testosterona (Testo) ao aparecimento os primeiros espermatozoides em machos da raça Nelore, em função da precocidade sexual.

\begin{tabular}{lccccc}
\hline Machos & Número & Idade $($ dias $)$ & CE $(\mathrm{cm})$ & Testo(ng/ml) & Peso $(\mathrm{kg})$ \\
\hline Precoces & 12 & $306,17 \pm 2,42^{\mathrm{a}}$ & $19,75 \pm 0,90^{\mathrm{a}}$ & $1,57 \pm 0,19$ & $273,30 \pm 18,69$ \\
Não Precoces & 53 & $375,45 \pm 5,71^{\mathrm{b}}$ & $22,11 \pm 0,35^{\mathrm{b}}$ & $1,62 \pm 0,19$ & $290,67 \pm 07,65$ \\
\hline
\end{tabular}

Valores acompanhados de letras diferentes, dentro da mesma coluna, são diferentes estatisticamente ao nível de 5\%, pelo teste de "T" 
A média de idade em que foi alcançada a precocidade sexual, medida pela presença dos primeiros espermatozoides no ejaculado, foi menor do que a descrita na literatura para animais da raça Nelore (Cardoso \& Godinho,1979: Silva et al.,1988; Frenau et al., 1996), porem semelhante a encontrada por Lunstra et al. (1978) em animais das raças Hereford e Brahman.

Os resultados obtidos sugerem que, independente da idade, o aparecimento dos primeiros espermatozoides é atingido, em média, num nível de testosterona, acima de $1 \mathrm{ng} / \mathrm{ml}$, e uma circunferência escrotal de cerca de $20 \mathrm{~cm}$, em média, este último resultado sendo menor do relatado por Frenau et al. (1996) e Unanian (1997). O nível de testosterona dos animais precoces e mesmo não precoces foi de acordo com o descrito na literatura para animais desta idade (Palasz et al., 1994). Estes resultados condizem ainda com os de Foote et al. (1976) que observaram que os níveis de testosterona variam significativamente com a idade, sendo mais baixos em animais jovens.

Da analise dos parâmetros estudados, em função da precocidade sexual, resultou, apenas em animais considerados precoces, uma correlação $(\mathrm{R}=0,34)$ entre o nível de testosterona o peso e a $\mathrm{CE}$, o que poderia indicar que animais que iniciam cedo a sua atividade sexual devem apresentar um desenvolvimento testicular e peso corporal suficiente e equilibrado.

\section{RESUMO}

O estudo foi desenvolvido em 79 bovinos machos da raça Nelore, PO, de dez a 16 meses de idade. Em todos os animais foram medidas a circunferência escrotal (CE), a concentração de testosterona (Testo) e o aparecimento dos primeiros espermatozoides no ejaculado. Os resultados indicaram que $18,5 \%$ dos machos em estudo apresentaram os primeiros espermatozoides aos $306,17 \pm 2,42$ dias de idade, $19,75 \pm 0,9 \mathrm{~cm}$ de circunferência escrotal, e uma concentração de testosterona de $1,57 \pm 0,9 \mathrm{ng} / \mathrm{ml}$. Após o aparecimento dos primeiros espermatozoides no ejaculado, os machos mostraram a puberdade aos $365,39 \pm 1,13$ dias e a maturidade aos 487,38 $\pm 3,08$ dias. Estes resultados indicam que existem machos na raça Nelore, PO que iniciam a atividade sexual em idades inferiores às descritas na literatura, sendo portanto considerados precoces.

\section{REFERÊNCIAS BIBLIOGRÁFICAS}

Amann, R.P. Endocrine changes associated with onset of spermatogenes in Holstein bulls. J. Dairy Sci., v.66, p.2606-2622, 1983.

Bailey, T.L.; Monke, D.; Hudson, R.S.;Wolfe, D.F. Testicular shape and its relationship to sperm production in mature Holstein bulls. Theriogenology, v.38, p.881887, 1996.

Cardoso, F.M.; Godinho, H.P. Morphological events of occurring in the seminiferous tubules of the brazilian Nelore zebu associated with puberty. Annatomische Anzeiger, v. 145, p.262-267, 1979.

Coulter, G.H.; Foote, R.H. Bovine testicular measurements as indicators of reproductive performance and their relationship to productive traits in cattle: a review. Theriogenology, v.11, n.4, p.297-311, 1979.

Curtis, S.K.; Amann, R.P. Testicular development and estabilishment of spermatogenesis in Holstein bulls. J. Anim. Sci., v.53, p. 1645-1652, 1981.

Entwistle, K. A brief update on male reproductive physiology. In: HOLROYD, R.G., ed. Bull fertility: proceedings of a workshop. Queensland: Department of Primary Industries, 1993. p.1-6.

Foote, R. H.; Munkenbech, N.; Greene, W. A. Testosterone and libido in Holstein bulls of various ages. J. Dairy Sci., v. 59, p.2011-2034, 1976.

Frenau, G. E.; Guimarães, J. D.; Vale Filho, V. R. Biópsia testicular aberta em touros Nelore: aspectos da puberdade seminal. In: CONGRESSO BRASILEIRO DAS RAÇAS ZEBUÍNAS, 2., 1996, Uberaba, MG. Anais...Uberaba, MG: ABCZ, 1996. Sp.

Ge, R. -S.; Shan, L. -X.; Hardy, M. P. Pubertal development of Leydig cells. In: PAYNE, A.H. ; HARDY, M.P.; RUSSELL, L.D., ed. The Leydig cell. Vienna, IL, : Cashe River, 1996. p.160-173. 
Lunstra., D. D.; Ford, J. J.; Echternkamp, S. E. Puberty in beef bulls: hormone concentrations growth, testicular development, sperm production and sexual aggressiveness in bulls of different breeds. $J$. Anim. Sci., v. 46, p.1054-1057, 1978.

Microcal Origin, Version 4.1, Northampton, MA: Microcal Software, 1996. 5 disquetes 3 $1 / 2 "$ ".

Palasz, A.T.; Cates, W. F.; Barth, A. D.; Mapletoft, R. J. The relationship between scrotal circunference and quantitative testicular traits in yearling beef bulls. Theriogenology, v.42, n.4, p.715-726, 1994.

Silva, A. E. D. F.; Dode, M. A. N.; Unanian, M. M. The establishment of puberty in Zebu bulls of the Nelore breed raised in Central Brazil. In: WORLD CONGRESS ON SHEEP AND BEEF CATTLE BREEDING, 3, 1988, Paris.
Proceedings...Paris: INRA, 1988. v.2, p.613616.

Swerdloff, R.S.; Wang,C.Clinical evaluation of Leydig cell function. In: PAYNE, A.H. ; HARDY, M.P.; RUSSELL, L.D. The Leydig cell. Vienna, IL, : Cashe River, 1996. p.160-173

Unanian, M.M. Precocidade sexual em machos da raça Nelore. Nelore, v. 6, n. 42, p.66-68, 1997.

Wolf, F. R.; Almquist, J. O.; Hale, E. B. Prepuberal behavior and puberal characteristics of beef bulls on high nutrient allowance. J. Anim. Sci., v.24, p.761-765, 1965. 